\title{
Epi Info Cloud Data Analytics to improve quality of HIV Surveillance in Vietnam.
}

\author{
Diep T. Vu¹, Duc H. Bui ${ }^{2}$, Giang T. Le', Hai K. Nguyen³, Duong C. Thanh, \\ Nghia V. Khuu ${ }^{5}$, Gerald Jones ${ }^{6}$ and Huong T. Phan ${ }^{2}$
}

${ }^{1}$ Centers for Disease Prevention and Control, Hanoi, Viet Nam; ${ }^{2}$ Vietnam Authority of HIV/AIDS Control, Hanoi, Viet Nam; ${ }^{3} \mathrm{Hanoi}$ Medical University, Hanoi, Viet Nam; ${ }^{4}$ National Institute of Hygiene and Epidemiology, Hanoi, Viet Nam; ${ }^{5}$ Pasteur Institute in Ho Chi Minh City, Ho Chi Minh, Viet Nam; ${ }^{6}$ Centers for Disease Control and Prevention, Atlanta, GA, USA

\section{Objective}

To use Epi Info Cloud Data Analytics (ECDA) to improve the management, quality and utilization of the Vietnam National HIV Surveillance data.

\section{Introduction}

HIV surveillance in Vietnam is comprised of different surveillance systems including the HIV sentinel surveillance (HSS). The HSS is an annual, multi-site survey to monitor HIV sero-prevalence and risk behaviors among key populations. In 2015, the Vietnam Administration on HIV/AIDS Control (VAAC) installed the Epi Info Cloud Data Analytics (ECDA), a free web-based analytical and visualization program developed by the Centers for Disease Control and Prevention $(\mathrm{CDC})^{(1)}$ to serve as an information management system for HIV surveillance. Until 2016, provincial surveys, recorded on paper, were computerized and submitted to VAAC, which was responsible for merging individual provincial datasets to form a national HSS dataset. Feedback on HSS issues were provided to provinces 3 to 6 months after survey conclusion. With the use of tablets for field data collection in 2017, provincial survey data were recorded electronically and transferred to VAAC at the end of each survey day, thus enabling instant updating of the national 2017 HSS dataset on daily basis. Upon availability of the national HSS dataset on VAAC's server, ECDA enhanced wider access and prompt analysis for staff at all levels (figure 1). This abstract describes the use of ECDA, together with tablet-based data collection to improve management, quality and use of surveillance data.

\section{Methods}

After the installation of the ECDA on VAAC's server in 2015, investments were made at all levels of the surveillance systems to build the capacity to operate and maintain the ECDA. These included trainings on programming, administration, and utilization of ECDA at the central level; creating a centralized database through abstracting and linking different surveillance datasets; developing analysis templates to assist provincial-specific reports; and trainings on access and use of the ECDA to provincial staff. One hundred and eighty five ECDA analyst accounts, authorized for submission, viewing and analysis of data, were created for surveillance staff in 63 provinces and 7 agencies. Six administrator accounts, created for users at central and regional level, were authorized for editing data and management of user accounts. In 2017, more ECDA activities were conducted to: (i) develop analysis dashboards to track progress and data quality of HSS provincial surveys; (ii) facilitate frequent data reviews at central and regional levels; (iii) provide feedback to provinces on survey issues including sample selection.

\section{Results}

Since 2015, separate national datasets including the HSS, HIV case reports, HIV routine program reports were systematically cleaned and merged to form a centralized national database, which was then centrally stored and regularly backed up. Access to the national database was granted to surveillance staff in all 63 provinces through 185 designated ECDA accounts. During the 2017 HSS surveys, 70 ECDA users in $20 \mathrm{HSS}$ provinces were active to manage and use the HSS data. Twelve weekly reviews of HSS provincial data were conducted at national level throughout the 2017 HSS survey. Ninety percent of provinces received feedback on their survey data as early as the first week of field data collection. The national 2017 HSS dataset and its analysis were available immediately after the completion of the last provincial survey, which was about 3 to 6 months quicker than reports of previous years. More importantly, the fresh results of the 2017 HSS survey were available and used for the 2018 Vietnam HIV national planning circle (table 1).

\section{Conclusions}

ECDA is a quick, relevant, free program to improve the management and analysis of HIV surveillance data. Using ECDA, it is easy to generate and modify analysis dashboards that enhances utilization of surveillance data. Successful administration and use of the ECDA during the 2017 HSS survey is positive evidence for Ministry of Health to consider institutionalization of the program in Vietnam surveillance systems.

Table 1: HIV surveillance data before and after using ECDA

\begin{tabular}{|c|c|c|c|}
\hline HIV surveillance data & Before 2015 & $\begin{array}{c}2015-2016 \\
\text { (ECDA) }\end{array}$ & $\begin{array}{c}\text { Since } 2017 \\
\text { (ECDA + tablets) }\end{array}$ \\
\hline \multicolumn{4}{|l|}{ Type of database } \\
\hline - Separate, annual datasets & $\checkmark$ & & \\
\hline - Linked, multiple year database & & $\checkmark$ & $\checkmark$ \\
\hline \multicolumn{4}{|l|}{ Access to national database } \\
\hline - Central & $\sqrt{ }$ & $v$ & $\checkmark$ \\
\hline - Regional & & $\checkmark$ & $\checkmark$ \\
\hline - Provincial & & $\mathrm{v}$ & v \\
\hline \multicolumn{4}{|l|}{ Data collection } \\
\hline - Paper-based & $v$ & v & \\
\hline - Tablet-based & & & $\sqrt{ }$ \\
\hline \multicolumn{4}{|l|}{ Timeliness of feedback to provinces } \\
\hline - Through data review during field data collection & None & None & $\begin{array}{c}\checkmark \\
\text { weekly }\end{array}$ \\
\hline - Through processing of the national data & $\begin{array}{l}6 \text { months*, in training of } \\
\text { next HSS round }\end{array}$ & $\begin{array}{c}\checkmark \\
3 \text { months* }\end{array}$ & $\begin{array}{c}\checkmark \\
0 \text { month*, during survey } \\
\text { implementation }\end{array}$ \\
\hline \multicolumn{4}{|l|}{ Data processing \& use in provinces } \\
\hline - Vary by province & $\checkmark$ & & \\
\hline $\begin{array}{l}\text { - Use of standard analysis templates to generate \& } \\
\text { share provincial reports }\end{array}$ & & $\checkmark$ & $\checkmark$ \\
\hline
\end{tabular}

*after the completion of provincial surveys 


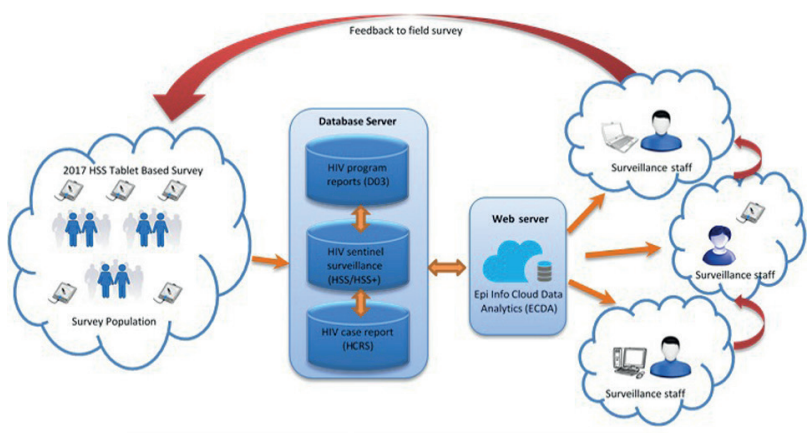

Figure 1: Overview of Epi Info Cloud Data Analytics (ECDA) to aid monitoring and data quality improvement of the Vietnam National HIV Sentinel Surveillance

\section{Keywords}

Health informatics; Epi Info; Management of surveillance data; HIV/ AIDS; sentinel surveillance

\section{Acknowledgments}

To surveillance staff at all level for their dedicated work on the HSS data. The technical assistance to Government of Vietnam to deploy ECDA and tablets has been supported by The United States President's Emergency Plan for AIDS Relief (PEPFAR) through the CDC.

\section{References}

1. CDC. ECDA software, https://www.cdc.gov/epiinfo/cloud.html.

\section{*Diep T. Vu}

E-mail: vubichdiep@hotmail.com 